\title{
Analysis of multipoint cutting tool temperature using FEM and CFD
}

\author{
Meenaskshi Sundaram Nagaraj ${ }^{1, *}$, Chakaravarthy Ezhilarasan ${ }^{2}$, A. John Presin Kumar $^{3}$, and Rishab Betala ${ }^{4}$ \\ ${ }^{1}$ Department of Mechanical Engineering, Hindustan University, Chennai, India \\ ${ }^{2}$ Department of Mechanical Engineering, SMK Fomra Institute of Technology, Chennai, India \\ ${ }^{3}$ Department of Mechanical Engineering, Hindustan Institute of Technology and Science, Chennai, India \\ 4 ARE PEE Polymer, Gummidhipoodhi, India
}

Received: 18 September 2018 / Accepted: 10 October 2018

\begin{abstract}
Nimonic C-263 is a British nickel-chromium-cobalt-molybdenum alloy specially meant to be used in high-temperature and high-strength applications. Consequently, it produces high thermo-mechanical loads on the machining tool when machined. As a result, excessive heat is generated during dry drilling, between Nimonic C-263 and tungsten carbide tool coated with Alcorna, which in turn reduces the durability of the tool. In order to determine the temperature distribution of the tool, the coupling of finite element machining simulations along with computational fluid dynamics simulations is performed. The temperature distribution of the tool under dry condition is simulated via the DEFORM 3D software and the Altair AcuSolve software. Further investigation under cooling condition is performed using Altair AcuSolve software. The mass flow rate of the coolants is kept constant when the temperature distribution is obtained during the CFD analysis under cooling condition. Silver nano coolant has high heat reduction compared to other coolants and is found to generate $34 \%$ less heat than dry condition.
\end{abstract}

Keywords: Nimonic C-263 / finite element machining / CFD / coolant / temperature

\section{Introduction}

While drilling, super alloys such as Nimonic C-263 generate high heat on the cutting zone and high tool wear. Simulations are performed under external cooling conditions using varied coolants. The effect of external cooling is analyzed in the simulations and their effect on the temperature distribution of the tool and the tool durability is also analyzed. Since the quantity of research conducted on external cooling of Nimonic C-263, and the effectiveness of the coolant is meager, we have conducted research in this area and have also analyzed and optimized the effect of coolant using this model. In AdvantEdge software, the boundary conditions for drilling are difficult to assign, and the interface between the tool and workpiece is complicated when compared to DEFORM 3D, and this leads to instability in the result. The machining during dry condition is validated with experiment and simulations.

The research in Aerospace industries at present is hindered in cooling technology with respect to external drilling of super alloys.

\footnotetext{
* e-mail: nagaraj_magic@yahoo.co.in
}

Salman et al. [1] proposed a technique to predict the temperature profile of the cutting tool during machining operations via a coupled FE and CFD modeling approach. The finite element modeling and the CFD analysis were performed via DEFORM 2D software and ANSYS CFX software. They simulated machining using Ti6Al4V and uncoated carbide as the workpiece and tool material, respectively. Air was utilized as a cooling media. The proposed method was used in predicting the temperature distribution of the cutting tool under the influence of a coolant using the ANSYS CFX software.

Muhammad et al. [2] conducted a study to determine the effect of cutting conditions such as feed rate and cutting speed on the temperature generated during the drilling process. They conducted the simulations using MSC MARC MENTAT on AISI 1010 steel and tungsten carbide as the tool material. The finite element simulations were experimentally verified using the drill bit on a lathe setup. The study concluded that there is an increase in temperature with respect to the increase in cutting speed and feed rate.

Fallenstein and Aurich [3] investigated the effect of the cutting fluid flow rate and cooling channel exit position in twist drills with internal cooling channels. They performed 
computational fluid dynamics simulations and found that the heat flux between the tool and coolant is influenced by the cutting flow rate along with the cooling channel exit position. Experiments with real flow conditions were also performed and the results were similar to the results obtained in the computational fluid dynamics simulations.

Ekrem et al. [4] conducted a study to determine the effect of coolant pressure and the coolant channel diameter of the twist drill on tool life and bore quality when drilling Inconel 718. Computational fluid dynamics simulations were performed, and the results showed that a higher mass flux of the coolant and the change in diameter of the coolant channel do not have any effect on the tool life, bore quality, and do not reduce the thermal loads. But when the coolant pressures were increased, there was a significant change in the tool life and the bore quality. The simulation results were corroborated with the experimental results by drilling Inconel 718 and taking SEM images of the twist drill used.

Dahu et al. [5] performed a study to determine the tool wear when machining nickel-based super alloys. They analyzed the tool life of various tools both coated and uncoated when machining Inconel 718. And they determined that the tool life can be improved by appropriately selecting the tool geometry, tool materials, tool coating, and cutting parameters. Cooling and lubrication of the tool under machining conditions have also been found to increase the tool life.

Minton et al. [6] experimentally determined the effect of cutting tool coating along with the use of internal cooled tools. They used diamond coated and uncoated cutting tools along with internal cooling and uncooled conditions to machine Titanium and found that heat extraction from the cutting was maximum when using diamond-coated drills with internal cooling, the results were verified by using thermal imaging cameras. They concluded that the use of internally cooled cutting tools along with indirect cooling showed an increase in tool life.

Ramesh et al. [7] also conducted experiments to analyze the effect of the cooling when drilling glass fiber-reinforced epoxy composites. The experiments were conducted by using TiN/TiAiN-coated tungsten carbide drills. They analyzed the drill temperature and damage factor for dry drilling, internal, and external cooling conditions. They also optimized the drilling conditions for both internal and external cooling conditions and reduced the drill temperature by 53 and $81 \%$ for internal and external cooling conditions when compared to dry drilling.

Siller et al. [8] performed experiments to determine the heat dissipated during the turning operations by using internal cooled cutting tools. They measured the temperature at the inlet and outlet of the cooling channels and found that the temperature of the tool tip were lower than the temperature obtained during dry machining. They concluded that by using the internal cooling, there was a definitive decrease in tool life.

Kumar and Ahmed [9] experimentally compared the effects of flood cooling with liquid nitrogen, when drilling AISI 304 stainless steel. The cutting temperature thrust force and surface roughness under both cooling conditions were analyzed. They concluded that when using liquid

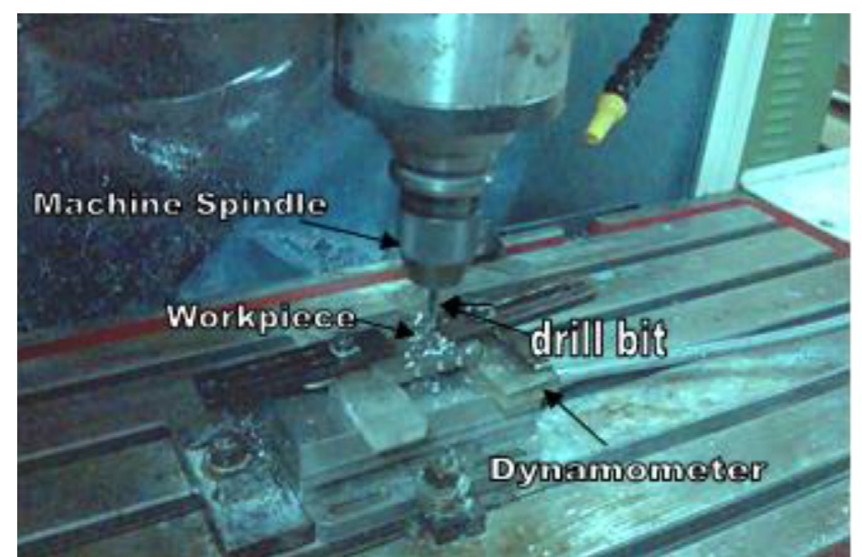

Fig. 1. Experimental setup.

nitrogen as a coolant, there was a decrease in cutting temperature by about $12-50 \%$, and it also increased the thrust force by about $4-12 \%$.

Attanasio et al. [10] simulated the tool wear using the finite element machining simulation when drilling Inconel 718. They used DEFORM 3D software to simulate the machining of Inconel 718. They concluded that tool wear increases as the cutting time is increased. They also conducted experiments with the same parameters as used in the simulation and found that the flank curves obtained were similar.

\section{Simulation methodology}

The coupled finite element machining simulations and computational fluid dynamics simulations are implemented in two stages accordingly. The first stage consists of conventional finite element machining simulation conducted using the Johnson-Cook material model under transient conditions. This modeling is executed using DEFROM 3D software. The temperature distribution of the dry drill generated in the cutting tool point is obtained in the first simulation stage.

The second stage consists of obtaining the temperature distribution from the dry drill condition as a heat source on the cutting tool point of the drill. Under these conditions, the CFD analysis is performed using various coolants with constant mass flow rate. There is a temperature reduction at the cutting tool point when various coolants are used.

\section{Experimental result under dry condition}

Drilling experiments were performed on Nimonic C-263 alloy specimens of $70 \mathrm{~mm}$ diameter and $10 \mathrm{~mm}$ thickness with a hardness of 32 HRC. Drilling trials have been conducted on ARIX (VMC 100) CNC vertical machining center. The experimental setup is shown in Figure 1. Considering the abrasive nature of the Nimonic alloys and the resultant generation of higher contact temperature between tool and work interface, $\mathrm{AlCrN}$-coated carbide drills were selected and used for drilling the workpiece. A pyrometer was used to measure the temperature at the 
Table 1. $\mathrm{L}_{27}$ orthogonal array.

\begin{tabular}{llllll}
\hline Levels & Control parameters & Unit & \multicolumn{2}{c}{ Levels } \\
\cline { 4 - 5 } & & & 1 & 2 & 3 \\
\hline 1 & Spindle speed $(N)$ & $\mathrm{rev} / \mathrm{min}$ & 750 & 1000 & 1250 \\
2 & Feed rate $(f)$ & $\mathrm{mm} / \mathrm{rev}$ & 0.05 & 0.10 & 0.125 \\
3 & Point angle $(2 \rho)$ & $\circ$ & 118 & 135 & 140 \\
\hline
\end{tabular}

Table 2. Experimental results.

\begin{tabular}{|c|c|c|c|c|}
\hline $\begin{array}{l}\text { Exp. } \\
\text { No. }\end{array}$ & $\begin{array}{l}\text { Speed } \\
(\mathrm{rev} / \mathrm{min})\end{array}$ & $\begin{array}{l}\text { Feed } \\
\text { rate } \\
(\mathrm{mm} / \mathrm{rev})\end{array}$ & $\begin{array}{l}\text { Point } \\
\text { angle } \\
\left({ }^{\circ}\right)\end{array}$ & $\begin{array}{l}\text { Temperature } \\
\left({ }^{\circ} \mathrm{C}\right)\end{array}$ \\
\hline 1 & 750 & 0.05 & 118 & 375 \\
\hline 2 & 750 & 0.05 & 135 & 410 \\
\hline 3 & 750 & 0.05 & 140 & 475 \\
\hline 4 & 750 & 0.10 & 118 & 470 \\
\hline 5 & 750 & 0.10 & 135 & 480 \\
\hline 6 & 750 & 0.10 & 140 & 520 \\
\hline 7 & 750 & 0.125 & 118 & 550 \\
\hline 8 & 750 & 0.125 & 135 & 560 \\
\hline 9 & 750 & 0.125 & 140 & 585 \\
\hline 10 & 1000 & 0.05 & 118 & 490 \\
\hline 11 & 1000 & 0.05 & 135 & 455 \\
\hline 12 & 1000 & 0.05 & 140 & 510 \\
\hline 13 & 1000 & 0.10 & 118 & 610 \\
\hline 14 & 1000 & 0.10 & 135 & 620 \\
\hline 15 & 1000 & 0.10 & 140 & 620 \\
\hline 16 & 1000 & 0.125 & 118 & 655 \\
\hline 17 & 1000 & 0.125 & 135 & 675 \\
\hline 18 & 1000 & 0.125 & 140 & 690 \\
\hline 19 & 1250 & 0.05 & 118 & 575 \\
\hline 20 & 1250 & 0.05 & 135 & 575 \\
\hline 21 & 1250 & 0.05 & 140 & 590 \\
\hline 22 & 1250 & 0.10 & 118 & 600 \\
\hline 23 & 1250 & 0.10 & 135 & 610 \\
\hline 24 & 1250 & 0.10 & 140 & 635 \\
\hline 25 & 1250 & 0.125 & 118 & 695 \\
\hline 26 & 1250 & 0.125 & 135 & 715 \\
\hline 27 & 1250 & 0.125 & 140 & 770 \\
\hline
\end{tabular}

Table 3. Material property of Nimonic C-263.

\begin{tabular}{ll}
\hline Property & Value \\
\hline Density & $8360 \mathrm{~kg} / \mathrm{m}^{3}$ \\
Young's modulus & $224 \mathrm{GPa}$ \\
Poisson's ratio & 0.3 \\
$C_{p}$ & $461 \mathrm{~J} / \mathrm{kg}{ }^{\circ} \mathrm{C}$ \\
Shear factor & 0.6 \\
\hline
\end{tabular}

cutting edge. Holes of $6 \mathrm{~mm}$ have been drilled under dry conditions. $\mathrm{L}_{27}$ orthogonal array was chosen to carry out the drilling trials. The experiments were conducted as shown in Table 1 , using the $\mathrm{L}_{27}$ Array. During the experimental trials, temperature of $635{ }^{\circ} \mathrm{C}$ was obtained at maximum spindle speed of $1250 \mathrm{rpm}$ and $0.1 \mathrm{~mm} / \mathrm{rev}$ feed rate. The temperature obtained in Deform 3D is $640{ }^{\circ} \mathrm{C}$. The temperature obtained is used to analyze the effect of coolants using the simulations in DEFORM 3D coupled with CFD. The experimental results are shown in Table 2 .

\section{DEFORM 3D simulation under dry condition}

The finite element model for machining is developed using DEFORM 3D software with Nimonic C-263 as the workpiece and tungsten carbide coated with Alcorna as the tool material. The properties of the material are listed in Table 3 . The flow model applied for Nimonic C-263 is the Johnson-Cook constitutive model. Equation (1) represents the Johnson-Cook model. The shear friction model is used to display the friction present at the tool-chip interface. The friction factor is 0.6 for tungsten carbide coated with Alcorna [11]. The Coulomb law is used for modeling the friction force as shown in equation (2).

$$
\sigma=\left[A+B p^{n}+C \ln \left(\frac{p}{\varepsilon_{0}}\right)\left[1-\left(\frac{\theta-\theta_{R}}{\theta_{m}-\theta_{R}}\right)^{m}\right]\right],
$$

where $A=450 \mathrm{Mpa}$ is the yield strength (MPa), $B=1700$ $\mathrm{MPa}$ is the hardening modulus (MPa), $C=0.017$ is the strain rate sensitivity coefficient, $n=0.65$ is the hardening coefficient, $m=1.3$ is the thermal coefficient, $\theta_{m}=$ melting temperature, and $\theta_{R}=$ initial temperature.

$$
f_{s}=\mu p .
$$

The CAD model of the drill and the workpiece is meshed with DEFORM 3D software as shown in Figure 2. The mesh properties are listed in Tables 4 and 5. The finite element machining model is used to determine the temperature distribution of the drill bit under the boundary conditions. The workpiece is fixed, and the tool is rotated during the machining process under dry cutting to determine the temperature distribution generated on the cutting tool. In FEA analysis, the machining parameters are as follows: spindle speed is $1250 \mathrm{rpm}$, feed rate is $0.1 \mathrm{~mm} / \mathrm{rev}$, and point angle is $140^{\circ}$. The result is obtained in 5000 time-steps and the temperature of the cutting tool 
Table 4. Drill bit parameters.

\begin{tabular}{ll}
\hline Drill bit diameter & $6 \mathrm{~mm}$ \\
\hline Point angle & 140 \\
Mesh element & Tetrahedral \\
Mesh size & 110 nodes \\
Relative mesh size & 35,000 \\
Size ratio & 5 \\
\hline
\end{tabular}

Table 5. Workpiece parameters.

\begin{tabular}{ll}
\hline Workpiece thickness & $10 \mathrm{~mm}$ \\
\hline Mesh element & Tetrahedral \\
Mesh size & 110 nodes \\
Relative mesh size & 2400 \\
Size ratio & 5 \\
\hline
\end{tabular}
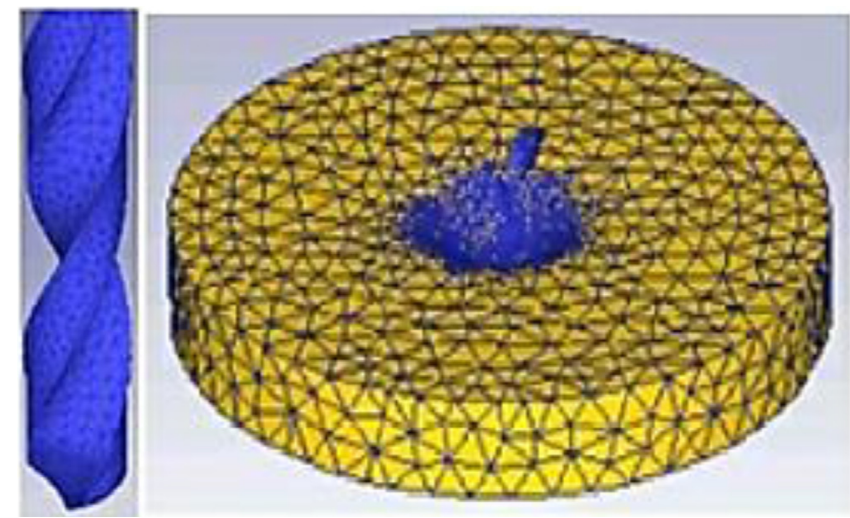

Fig. 2. Mesh of the drill and workpiece.

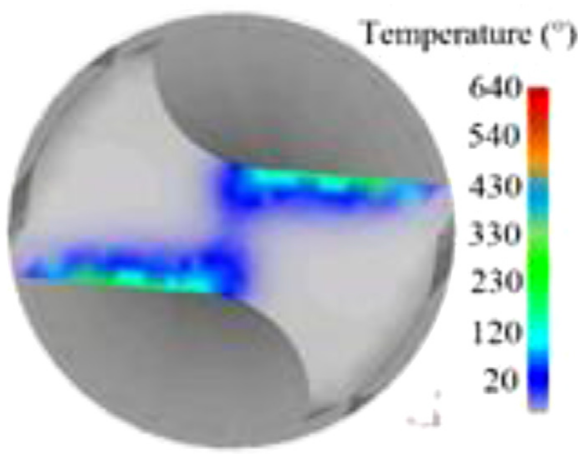

Fig. 3. Temperature distribution of the cutting tool.

obtained from the simulations is $640{ }^{\circ} \mathrm{C}$ as shown in Figure 3 and the corresponding chip removed during the drilling process is shown in Figure 4. The temperature obtained from the dry cutting condition is used as the heat source on the drill point during second stage of the simulation.

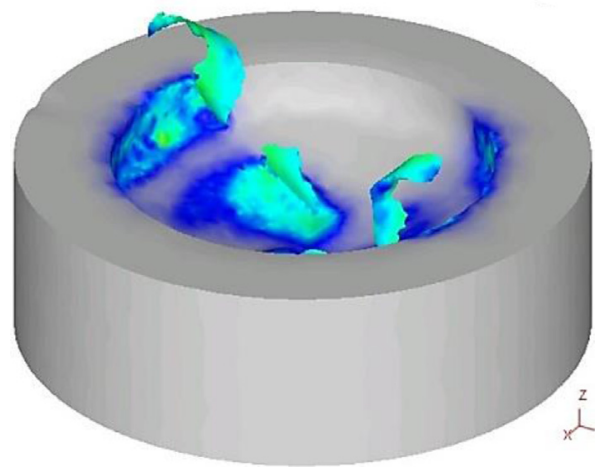

Fig. 4. Chip removed during drilling with spindle speed $=1250$ $\mathrm{rpm}$, and feed rate $=0.1 \mathrm{~mm} / \mathrm{rev}$.

\section{Altair AcuSolve simulation under cooling condition}

Altair AcuSolve CFD software is utilized to analyze the thermal effect of the heat generated during drilling and the effect of coolant on the tool temperature. The Altair AcuSolve CFD software solves Navier-Stokes equations.

The Altair AcuSolve software yields automated meshing solutions to reduce the pre-processing time. The software also provides a robust solution irrespective of the mesh characteristics. Fully coupled pressure--velocity and temperature-flow systems can be solved rapidly. CFD simulation is done in AcuSolve solver and AcuSolve is built around the Navier-Stokes equations, which describe the properties of viscous flows.

\section{Methodology}

The steps required to perform the simulation are generation of a CAD model, discretization of the CAD model, and definition of the boundary conditions and material properties. The drill bit and workpiece CAD files are imported and meshed in Altair AcuSolve with the same parameters used in the DEFORM 3D software as shown in Figure 5. The boundary condition considering the flow as transient state and Spalart-Allmaras model with a relaxation factor of 0.6 are as follows: Convective heat transfer coefficient is considered as $70 \mathrm{~W} / \mathrm{m}^{2} \mathrm{~K}$ for the outer drill bit and for the drill bit part that is inside the workpiece considered for $10 \mathrm{~W} / \mathrm{m}^{2} \mathrm{~K}$. The main settings for the meshing of solid and fluid domain are tetrahedrons with sizes ranging from $5 \mathrm{e}-4 \mathrm{~m}$ to $3 \mathrm{e}-3 \mathrm{~m}$ generating $10,71,906$ number of elements. The temperature distribution determined from the DEFORM 3D simulation as $914 \mathrm{~K}$ is assigned at the flank of the drill bit.

\section{Cooling conditions}

The drill bit is subjected to machining conditions by drilling Nimonic C-263. The heat is generated due to the 
Table 6. Coolant properties.

\begin{tabular}{llll}
\hline Property & Water & Soluble oil & Silver nano \\
\hline Density & $1000 \mathrm{~kg} / \mathrm{m}^{3}$ & $981 \mathrm{~kg} / \mathrm{m}^{3}$ & $1060 \mathrm{~kg} / \mathrm{m}^{3}$ \\
$C_{p}$ & $4185 \mathrm{~J} / \mathrm{kg} \mathrm{K}$ & $4006 \mathrm{~J} / \mathrm{kg} \mathrm{K}$ & $2841 \mathrm{~J} / \mathrm{kg} \mathrm{K}$ \\
Thermal conductivity & $0.608 \mathrm{~W} / \mathrm{mK}$ & $0.59 \mathrm{~W} / \mathrm{mK}$ & $430 \mathrm{~W} / \mathrm{m} \mathrm{K}$ \\
Viscosity & $0.889 \mathrm{Ns} / \mathrm{m}^{2}$ & $1061 \mathrm{e}-6 \mathrm{Ns} / \mathrm{m}^{2}$ & $175 \mathrm{e}-5 \mathrm{Ns} / \mathrm{m}^{2}$ \\
\hline
\end{tabular}

Table 7. Change in temperature difference with respect to the coolant.

\begin{tabular}{llll}
\hline Coolant & Temperature & \% Reduction in temperature \\
\hline & $\mathrm{K}$ & ${ }^{\circ} \mathrm{C}$ & \\
Air & 914 & 641 & $26.05 \%$ \\
Water & 747 & 474 & $30.58 \%$ \\
Oil & 718 & 445 & $34.95 \%$ \\
Nano & 690 & 417 & \\
\hline
\end{tabular}

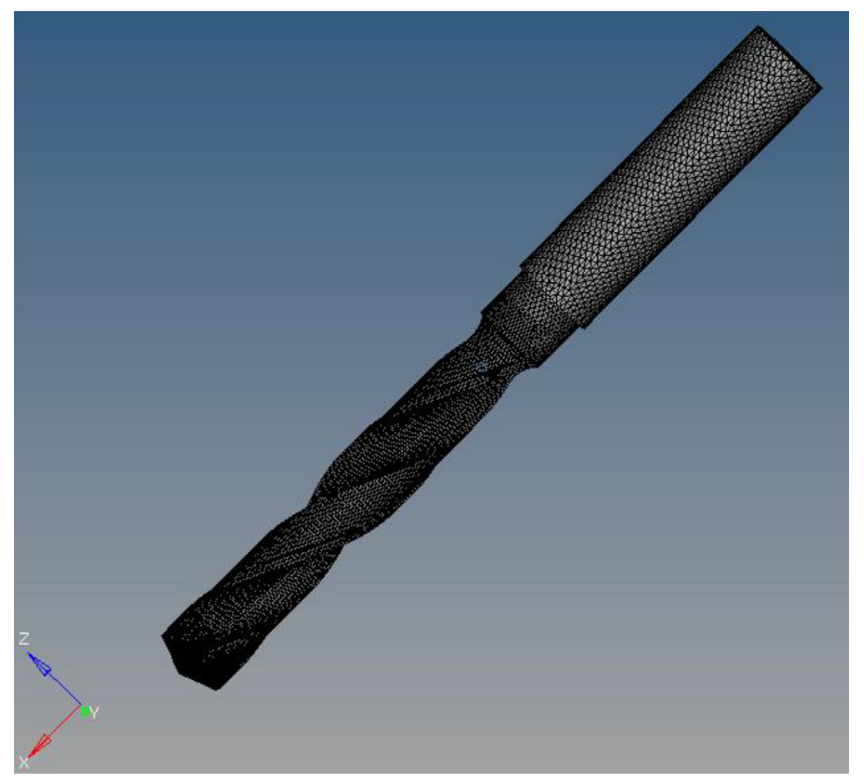

Fig. 5. Mesh of the drill bit.

interaction between the flank of the drill and the chip. The drilling is subjected to cooling conditions by using coolant such as water, soluble oil, and nano fluids. The temperature distribution obtained from the dry cutting displays that the maximum temperature obtained is $914 \mathrm{~K}$ and the minimum temperature is $294 \mathrm{~K}$. The drilling operation is performed with different coolants with the same mass flow rate of $125 \mathrm{ml} / \mathrm{h}$ feed rate of $0.1 \mathrm{~mm} / \mathrm{rev}$ and spindle speed of $1250 \mathrm{rpm}$.

The maximum flank temperature while using water, soluble oil, and nano are 747, 718, and $690 \mathrm{~K}$, respectively, as shown in Figure 6. The properties of the various coolants are given in Table 6 . The percentage variation between the temperatures is given in Table 7 .

The simulations are performed under constant mass flow rate to determine the percentage of temperature reduction while using various coolants. When water is used as a coolant during the drilling process, it is incapable to transport heat effectively because, during the machining of Nimonic C-263, there is high heat generated at the drill tip that is of the magnitude of $640^{\circ} \mathrm{C}$, which is higher than the boiling point of water. Therefore, the water applied evaporates without cooling the cutting zone and the heat is reduced by only $26 \%$ when compared to the dry condition. Further analysis is done using soluble oil, a viscous fluid. Soluble oil due to its high viscosity flows between the drill flank and the workpiece; since the machining time is $5 \mathrm{~s}$ and the mass flow rate of the coolant is $125 \mathrm{ml} / \mathrm{h}$, the soluble oil is not capable of wetting the cutting zone and transporting heat away from the cutting zone. The silver nano, on the other hand, has high wettability, resulting in high heat transfer rates between the tool and workpiece, and thus the percentage of heat reduction is higher than both water and soluble oil. Therefore, the rate of heat dissipation is high, and the tool life is extended.

When coolants such as water or soluble oil are used, there is also a risk of overheating the drill bit, consequently damaging the drill. The utilization of silver nano coolant prevents overheating of the drill. There is also a decrease in the friction between the tool and the workpiece due to the low shear factor. This results in the decrease of cutting force, which further increases the tool life. Because of these properties, the silver nano coolant can be used in the drilling of the Nimonic C-263 alloy. 


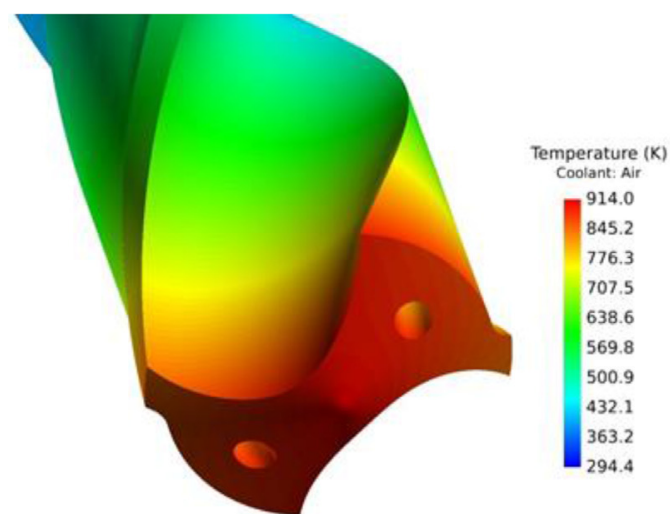

A

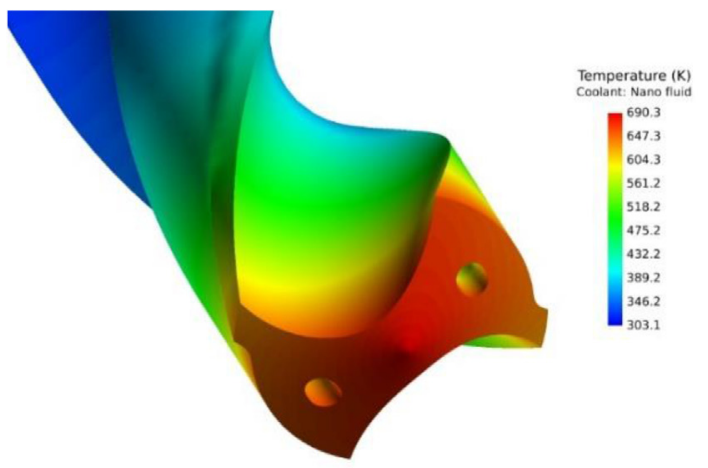

C

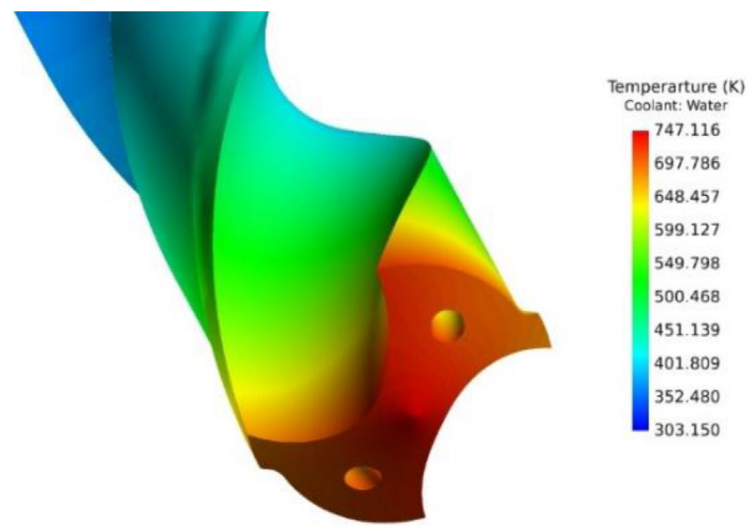

B

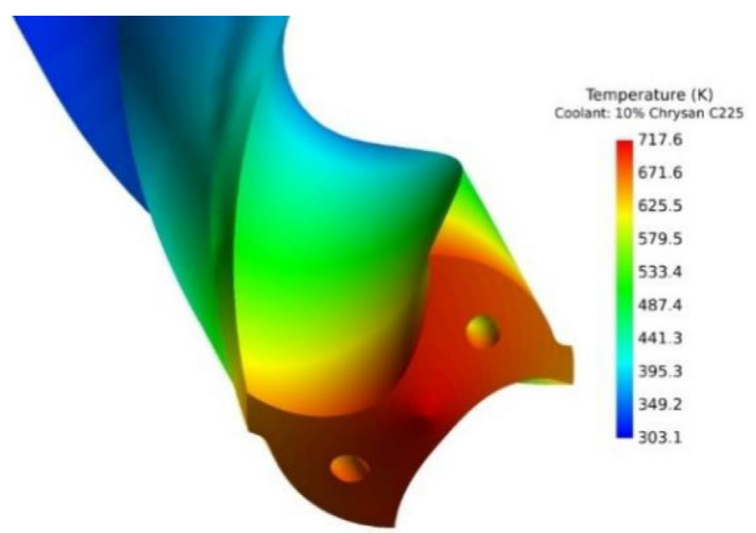

$\mathrm{D}$

Fig. 6. Flank temperature when using air (a), water (b), silver nano coolant (c), and soluble oil (d).

\section{Conclusion}

When working under external cooling conditions, the temperature distribution of the drill bit can be predicted using finite element methods coupled with computational fluid dynamics. This method can be applied for analyzing the effect of various coolants on the temperature of the drill or any other machining process. The simulations also show a decrease in the temperature distribution of the drill when machining under the influence of various coolants. There is a minimum change of $26 \%$ and a maximum change of $34 \%$ when using water and silver nano, respectively, when compared to the dry cutting conditions. There is also an increase in tool life during the machining operation when using silver nano coolant. This is due to the low friction between the tool and the workpiece. Thus, silver nano is the most efficient coolant for the heat, temperature distribution, and tool life issues. The effectiveness of new coolants can be analyzed for machining operations using this model. Aerospace industries can easily optimize the coolant for the machining conditions under external cooling for drilling of super alloys.

\section{References}

1. S. Pervaiza, I. Deiabb, E.M. Wahba, A. Rashida, M. Nicolescua, A coupled FE and CFD approach to predict the cutting tool temperature profile in machining, Procedia CIRP 17 (2014) 750-754

2. R. Muhammad, N. Ahmed, Y.M. Shariff, V.V. Silberschmidt, Effect of cutting conditions on temperature generated in drilling process: a FEA approach, Adv. Mater. Res. 223 (2011) 240-246

3. F. Fallenstein, J.C. Aurich, CFD-based investigation on internal cooling of twist drills, Procedia CIRP 14 (2014) 293298

4. E. Oezkaya, N. Beer, D. Biermann, Experimental studies and CFD simulation of the internal cooling conditions when drilling Inconel 718, Int. J. Mach. Tools Manuf. 108 (2016) 52-65

5. D. Zhu, X. Zhang, H. Ding, Tool wear characteristics in machining of nickel-based superalloys, Int. J. Mach. Tools Manuf. 64 (2013) 60-77

6. T. Minton, S. Ghani, F. Sammler, R. Bateman, P. Fürstmann, M. Roeder, Temperature of internally cooled diamond-coated tools for dry cutting titanium, Int. J. Mach. Tools Manuf. 75 (2013) 27-35 
7. B. Ramesh, A. Elayaperumal, S. Satishkumar, K. Anish, T. Jayakumar, D. Dinakaran, Influence of cooling on the performance of the drilling process of glass fiber-reinforced epoxy composites, Arch. Civil Mech. Eng. 16 (2016) 135-146

8. S. Anton, S. Andreas, B. Friedrich, Heat dissipation in turning operations by means of internal cooling, Procedia Eng. 100 (2015) 1116-1123

9. M. Pradeep Kumar, L. Shakeel Ahmed, Drilling of AISI 304 stainless steel under liquid nitrogen cooling: a comparison with flood cooling, Mater. Today 4 (2017) $1518-1524$

10. A. Attanasio, F. Faini, J.C. Outeiro, FEM simulation of tool wear in drilling, Procedia CIRP 58 (2017) 440-444

11. C. Ezilarasan, V.S. Senthil Kumar, A. Velayudham, Theoretical predictions and experimental validations on machining the Nimonic C-263 super alloy, Simul. Model. Pract. Theory 40 (2014) 192-207

Cite this article as: M.S. Nagaraj, C. Ezilarasan, A. John Presin Kumar, Rishab Betala, Analysis of multipoint cutting tool temperature using FEM and CFD, Manufacturing Rev. 5, 16 (2018) 